\title{
ENIGE MACRO-ECONOMISCHE SIMULATIESTUDIES
}

\author{
door Drs. C. van de Panne
}

Inhoud

1. Inleiding

2. Simulatie met een economisch model

3. Een simulatiestudie van het Klein-Goldberger model

4. Een simulatie van een teruggang in de Amerikaanse economie

5. Een simulatie met een ,computer model" voor een onderontwikkeld land

6. Enige slotopmerkingen

Literatuur

\section{Inleiding}

Een vaak aangehaald verschil tussen de economische wetenschap en de natuurwetenschappen is dat in de economie (vrijwel) geen experimenten mogelijk zijn, terwijl deze in de natuurwetenschappen en hun toepassingen een belangrijke rol spelen. Men kan bijv. de uitzetting van een metaal door temperatuurstijging nagaan door onder nauwkeurig gecontroleerde voorwaarden een stuk van dat metaal te verwarmen en de uitzetting ervan te meten. Het is echter niet mogelijk de marginale consumptiequote te meten door het nationaal inkomen te variëren.

Hoewel men in het algemeen niet met een reële economie of met een deel daarvan kan experimenteren, kan men dit wel doen met een model van de economie. Zulk een model kan verbaal zijn en in woorden de relatie tussen de verschillende variabelen weergeven. Het kan echter ook een wiskundige vorm hebben, waarbij de relaties tussen de variabelen met behulp van vergelijkingen worden weergegeven. De twee manieren van weergave zijn in wezen equivalent, hoewel de wiskundige weergave compacter is.

Het numeriek experimenteren met een model wordt simulatie genoemd. De aard van deze experimenten zal in het onderstaande worden duidelijk gemaakt. Het spreekt vanzelf dat bij simulatie het model wiskundig gespecificeerd moet zijn. Simulatie zal in het algemeen veel rekenwerk met zich meebrengen en het is om deze reden dat men hierbij vrijwel steeds een automatische rekenmachine nodig heeft. Het overgrote deel van de simulatiestudies zou zonder het gebruik van deze machines onuitvoerbaar zijn, daar het onmogelijk zou zijn rekenwerk van deze omvang op een tafelrekenmachine uit te voeren, afgezien dan nog van de kosten die daaraan verbonden zouden zijn.

De ontwikkeling van de electronische rekenmachines heeft het mogelijk gemaakt modellen te construeren van veel grotere omvang en complexiteit. Een aantal van deze modellen is alleen te gebruiken voor simulatiedoeleinden; deze modellen bestaan veelal alleen in de taal van de rekenmachine; dit zijn de zg. computer-models. Weergave van deze modellen, hetzij verbaal hetzij in de gebruikelijke wiskundige formulering, zou te omslachtig zijn.

In het bestek van een kort artikel is het niet mogelijk in te gaan op de overeenkomsten van en de verschillen tussen simulatie en aanverwante technieken, zoals die van de beleidsspelen (business games) en Monte-Carlo methoden. We volstaan hier met op te merken dat in de beleidsspelen een essentieel element wordt gevormd door de deelname van de spelers; d.w.z. dat de reakties van reële personen 
een essentieel onderdeel zijn van het model. Monte-Carlo methoden berusten op het gebruik van willekeurige getallen en worden vaak gebruikt in de mathematische statistiek ${ }^{1}$ ). Bij simulatie kan gebruik gemaakt worden van willekeurige getallen. doch dit is niet noodzakelijk.

In de volgende paragrafen zullen, nadat simulatie in een economisch model wat uitvoeriger besproken is, drie macro-economische simulatiestudies naar voren gebracht worden, waarbij enige aandacht wordt besteed aan het gebruik van simulatiemethoden voor de economische politiek en waarbij een vergelijking gemakkt wordt met het gebruik van lineaire beslissingsregels.

\section{Simulatie met een economisch model}

Indien het model erg eenvoudig is, zijn de numerieke experimenten van de simulatie niet erg interessant en eigenlijk overbodig. Nemen we bijv. het allereenvoudigste macro-economische model, nl. het multiplicator-model van Keynes, dat als volgt geformuleerd kan worden. De consumptiefunktie is

(1)

$$
\mathrm{C}=\mathrm{cY} \text {, }
$$

waarbij $C$ de consumptieve bestedingen voorstelt, $Y$ het nationaal inkomen en $c$ de marginale consumptiequote. De definitievergelijking van het nationaal inkomen is

$$
\mathrm{Y}=\mathrm{C}+\mathrm{I} \text {, }
$$

waarbij I de investeringen voorstelt die exogeen (autonoom) verondersteld worden te zijn. Indien $\mathrm{C}$ met behulp van de eerste vergelijking uit de tweede wordt geëlimineerd, vinden we na oplossing van de resulterende vergelijking voor $Y$ :

$$
\mathrm{Y}=\frac{1}{1-\mathrm{c}} \mathrm{I} \text {. }
$$

Volgens deze vergelijking is het verloop van het nationale inkomen (in de evenwichtstoestand) evenredig met dat van de investeringen. De evenredigheidsfactor is $1 / 1-c$; deze factor wordt de multiplicator genoemd.

$\mathrm{Nu}$ is het duidelijk dat met dit eenvoudige model niet veel te experimenteren valt. Indien bijv. de marginale consumptiequote 0,8 is, is de multiplicator 5 ; we weten dan dat voor elk niveau van de investeringen het bijbehorende niveau van het nationale inkomen vijfmaal zo groot is. Simulatie zou in dit geval betekenen dat men waarden voor I aannam, waarna men de bijbehorende waarden voor $Y$ berekende, gegeven een waarde of een aantal waarden voor c. Vergelijking (3) echter geeft het verband tussen $\mathrm{Y}$ en I op zulk een eenvoudige wijze weer dat de berekening van $Y$ voor specifieke waarden van I overbodig is.

Het multiplicator-model is echter het eenvoudigste macro-model dat men zich denken kan, en wat in een eenvoudig model triviaal is kan men in meer gecompliceerde modellen slechts met veel moeite of in het geheel niet bereiken. Economische modellen (en hierbij doelen we in het bijzonder op macro-economische modellen) zijn als regel veel gecompliceerder dan het Keynesiaanse multiplicator-model. Deze complicaties zijn van verschillende aard. We kunnen vier soorten complicaties onderscheiden.

Ten eerste zijn de meeste modellen veel groter, d.w.z. ze bevatten meer vergelijkingen in meer te verklaren variabelen, terwijl er ook meer exogene variabelen in voorkomen. Nu kan men, indien de vergelijkingen lineair zijn, de en-

1) Voor een voorbeeld van een zeer eenvoudige toepassing, zie [10].

m a b blz. 88 
dogene variabelen oplossen uit de vergelijkingen en aldus uitdrukkingen verkrijgen voor elk der endogene variabelen; deze uitdrukkingen geven weer hoe de endogene variabelen afhankelijk zijn van de exogene variabelen en van de coëfficienten van de vergelijkingen In dit geval is het niet meer zo triviaal numeriek na te gaan hoe de waarde van de endogene variabelen verandert als een of meer waarden van de exogene variabelen veranderen of als coëfficiënten van de vergelijkingen een andere waarde aannemen. Een expliciete wiskundige afleiding van deze veranderingen is echter zeer eenvoudig voorzover de gevolgen van verandering in de exogene variabelen worden nagegaan; ook hier heeft simulatie niet veel zin. De gevolgen van veranderingen van de coëfficiënten zijn moeilijker na te gaan, zodat simulatie in deze gevallen al van meer betekenis is.

Ten tweede is het merendeel der modellen dynamisch. Het multiplicator-model is statisch en is dus alleen geldig onder evenwichtsvoorwaarden. Dynamische modellen, waarin dus variabelen voorkomen die op verschillende perioden betrekking hebben, zijn van meer belang. Een eenvoudig voorbeeld van een dynamisch model is het volgende multiplicator-accelerator model van Samuelson ${ }^{2}$ ). De consumptiefunktie is in dit geval

$$
\mathrm{C}_{\mathrm{t}}=\overline{\mathrm{C}}_{\mathrm{t}}+\mathrm{cY} \mathrm{Y}_{\mathrm{t}-1}
$$

$\overline{\mathrm{C}}_{\mathrm{t}}$ geeft de autonome consumptie in periode $t$ weer. Men ziet dat de variabelen nu betrekking hebben op verschillende perioden. De investeringen zijn in dit model niet autonoom, maar bevatten een autonoom gedeelte en een gedeelte dat evenredig is met de toename van de consumptie:

$$
\mathrm{I}_{\mathrm{t}}=\overline{\mathrm{I}}_{\mathrm{t}}+\mathrm{b}\left(\mathrm{C}_{\mathrm{t}-1}-\mathrm{C}_{\mathrm{t}-2}\right) \text {; }
$$

$\overline{\mathrm{I}}_{\mathrm{t}}$ geeft de autonome investeringen weer en $\mathrm{b}$ de evenredigheidsfactor. Het nationaal inkomen wordt gegeven door de definitievergelijking

$$
Y_{t}=C_{t}+I_{t}+G_{t}
$$

waarbij $G_{t}$ de overheidsuitgaven in periode $t$ voorstelt, die exogeen verondersteld worden.

Volgens (4) is $C_{t}$ afhankelijk van $Y_{t-1}$; volgens (6) is $Y_{t-1}$ afhankelijk van $C_{t-1}, I_{t-1}$ en $Y_{t-1}$. Men kan dan gemakkelijk nagaan dat alle endogene variabelen $C_{t}, I_{t}$ en $Y_{t}$ afhankelijk zijn van alle exogene variabelen $\bar{C}_{\tau}, \bar{I}_{\tau}$ en $C_{\tau}$ voor $\tau \leqq t$. Neemt men als beginperiode $O$ aan, dan zijn de endogene variabelen voor periode $t$ afhankelijk van de exogene variabelen in de periode 1 tot $t$ en de beginwaarden van de endogene variabelen $C_{0}, I_{0}$ en $Y_{0}$. Het is mogelijk een expliciete uitdrukking te geven voor de endogene variabelen in de exogene variabelen van alle perioden en de endogene variabelen in de beginperiode; deze formulering wordt de finale vorm van het model genoemd ${ }^{3}$ ). Deze uitdrukking is echter tamelijk ingewikkeld en als de beginwaarden van de endogene variabelen en alle exogene variabelen bekend zijn is het veel gemakkelijker de simulatie-aanpak te volgen. Hierbij gaat men als volgt te werk. Daar $C_{0}$ en $Y_{0}$ bekend zijn, kan men met behulp van (4), (5) en (6) $C_{1}, I_{1}$ en $Y_{1}$ berekenen. Daarna berekent men op dezelfde wijze $\mathrm{C}_{2}, \mathrm{I}_{2}$ en $\mathrm{Y}_{2}$. Men herhaalt dit tot men op deze wijze alle endogene variabelen in de perioden 1 tot $t$ berekend heeft. Men kan dezelfde berekeningen herhalen voor verschillende reeksen van exogene variabelen en voor verschillende waarden van $c$ en $b$.

2) Aan het model zijn enkele autonome termen toegevoegd om de rol die de exogene variabelen spelen beter te doen uitkomen.

3) Zie Theil en Boor [14]. 
Door realistische reeksen van exogene variabelen te kiezen, kan men een indruk krijgen van de realiteitswaarde van het model; indien men namelijk voor realistische waarden van exogene variabelen onrealistische reeksen van endogene variabelen verkrijgt, dan is het model kennelijk niet zeer realistisch. Verder kan men verschillende waarden voor de overheidsuitgaven in de opeenvolgende perioden kiezen om de gevolgen van veranderingen in de overheidsuitgaven op het nationaal inkomen na te gaan. Het is mogelijk om door een wiskundige analyse van het model de algemene eigenschappen van een model na te gaan; bijvoorbeeld, men kan nagaan of het model stabiel is of onstabiel, of er een impliciete fluctuatie is, en zo ja, welke de periode is van deze fluctuatie. Deze eigenschappen gelden onder allerlei omstandigheden, d.w.z. voor alle waarden van de exogene variabelen. Simulatie echter concentreert zich op de gevolgen voor de endogene variabelen voor realistische waarden van de exogene variabelen. Daarom heeft simulatie zelfs voor eenvoudige lineaire dynamische stelsels zin.

Ten derde bevat een aantal modellen, waaronder zeker niet de minst realistische, een of meerdere vergelijkingen die niet-lineair zijn. Een eenvoudig voorbeeld is de waarde - prijs - hoeveelheid indentiteit:

$$
\mathrm{w}=\mathrm{pv} \text {, }
$$

waarbij $\mathrm{w}$ de waarde, $\mathrm{p}$ een prijs en $\mathrm{v}$ de hoeveelheid van de produktie van een goed voorstelt; indien $\mathrm{p}$ en $\mathrm{v}$ beide endogeen zijn, zijn de vergelijking en het stelsel dat deze vergelijking bevat, niet-lineair. In micro-modellen vindt men vaak nonlineariteiten van de volgende aard. Als aan een bepaalde ongelijkheid voldaan is, is een zekere vergelijking geldig, terwijl in het geval aan de vergelijking niet voldaan is, een alternatieve vergelijking geldt. Op deze wijze kan men bijv. geknikte vraagcurven en plafonds voor bepaalde variabelen introduceren. Nietlineaire stelsels zijn in het algemeen moeilijk te analyseren met een analytische wiskundige aanpak, terwijl in het geval ongelijkheden in het spel komen, de gebruikclijke wiskundige aanpak op zeer grote moeilijkheden stuit. In deze gevallen is de simulatie-aanpak van grote waarde. Ongelijkheden veroorzaken niet veel moeilijkheden bij simulatie, terwijl men in het algemeen niet-lineaire vergelijkingen kan lineariseren, omdat het toch steeds gaat om de waarde van de endogene variabelen bij numeriek gegeven waarden van de exogene variabelen.

De vierde complicatie wordt gevormd door het element van onzekerheid in de modellen. Om deze onzekerheid weer te geven heeft men bijv. in plaats van de consumptiefunktie in (4) de volgende funktie

$$
\mathrm{C}_{\mathrm{t}}=\overline{\mathrm{C}}_{\mathrm{t}}+\mathrm{c} \mathrm{Y}_{\mathrm{t}-1}+\mathrm{u}_{\mathrm{t}}
$$

waarbij $u_{t}$ een willekeurig getal is dat verschillende waarden kan aannemen met gegeven waarschijnlijkheden. In andere vergelijkingen van het model kunnen soortgclijke termen optreden. De simulatie-aanpak is in dergelijke gevallen zeer nuttı aangezien de formele econometrische behandeling op moeilijkheden kan stuiten. In de simulatie-aanpak worden derhalve, behalve de waarden van de exogene variabelen over de gehele periode, ook reeksen van willekeurige getallen gebruikt (die natuurlijk aan zekere voorwaarden, bijv. wat betreft gemiddelde en standaarddeviatie, moeten voldoen). Men moet natuurlijk een experiment met willekeurige getallen een aantal malen met verschillende reeksen willekeurige getallen (met dezelfde eigenschappen) herhalen om een goede indruk te krijgen van de werking van het model. Deze laatste factor van de onzekerheid heef de simulatie-aanpak gemeen met de Monte-Carlo methoden. In sommige studies is het werken met willekeurige getallen essentieel, in andere komt het niet voor.

$\mathrm{mab}$ blz. 90 


\section{Een simulatiestudie van het Klein-Goldberger model}

Het doel van simulatie met een economisch model kan van tweeërlei aard zijn. Ten eerste kan de simulatie ten doel hebben na te gaan of een model een goede weergave is van de werkelijkheid; in dit geval staat de simulatie in dienst van de economische analyse. Ten tweede kan de simulatie dienen om economische maatregelen uit te proberen; de simulatie staat dan in het teken van de economische politiek. In het eerste geval is het het model waarvan men de waarde wil toetsen; in het tweede geval neemt men aan dat het model juist is en wil men op basis hiervan de verschillende maatregelen van de economische politiek vergelijken.

De eerste simulatie die hier behandeld wordt heeft het eerstgenoemde doel. Het is een simulatie-studie van een model van de Amerikaanse economie van Klein en Goldberger door Adelman en Adelman [1]. Het zg. Klein-Goldberger model is een econometrisch model gebaseerd op waarnemingen gedurende de periode 19291952 , zie [8]. Het is een dynamisch model dat bestaat uit 25 vergelijkingen, waarvan enkele niet-lineair. Het model bevat storingstermen in de vergelijkingen, zodat alle vier soorten complicaties waarvan in de vorige paragraaf sprake was, aanwezig zijn. Het doel van de studie was na te gaan of de dynamische eigenschappen van het Klein-Goldberger model verenigbaar waren met de conjunctuurfluctuaties. Met andere woorden, kan het Klein-Goldberger model fluctuaties doen ontstaan van dezelfde soort als die zich in de werkelijkheid voordoen. In de werkelijkheid doen zich fluctuaties voor met een min of meer constante periode en amplitude.

Dezelfde vraag kan beantwoord worden met de meer gebruikelijke wiskundige technieken. Goldberger [6] heeft zich met een wiskundige analyse van het KleinGoldberger model bezig gehouden en het is dus interessant de resultaten van de twee aanpakken te vergelijken.

De auteurs van de simulatie-studie zijn als volgt te werk gegaan. Daar men de waarden van de exogene variabelen over de gehele periode nodig heeft, heeft men de trend-waarden van deze variabelen voor de naoorlogse periode geëxtrapoleerd over 100 jaar; deze trendwaarden heeft men dan gebruikt voor het vinden van de waarden van de endogene variabelen over de periode van 100 jaar. De berekening van deze variabelen heeft plaats voor achtereenvolgende jaren, zoals beschreven in de vorige paragraaf; de berekening werd gecompliceerd door de aanwezigheid van niet-lineaire vergelijkingen. De storingstermen werden steeds 0 verondersteld. Het resultaat van deze simulatie over 100 jaar was dat men reeksen van de endogene variabelen verkreeg, die een louter trendmatig verloop hadden. Dit komt natuurlijk niet erg overeen met de werkelijkheid.

Men ging ook na hoe het model reageert op een grote schok in de exogene variabelen. De overheidsuitgaven werden verondersteld in een bepaald jaar met meer dan $25 \%$ te dalen; in het volgend jaar had het overheidsbudget weer de normale grootte. Het gevolg was een diepe depressie, die echter van zeer korte duur was. Hoewel er wel sprake was van enige fluctuatie was deze sterk gedempt en de economie keerde snel terug naar de trend. Het bleek dat het model zeer stabiel is. $\mathrm{Nu}$ kan een redelijk stabiel model alleen fluctuaties vertonen, indien er zich steeds exogene schokken voordoen.

We kunnen deze resultaten vergelijken met die van Goldberger [6] die de gebruikelijke wiskundige analyse volgde. Zijn methode berust op het lineariseren van het model. Het bleek dan noodzakelijk om het model te splitsen in een reële 
sector en een monetaire sector, waarbij de reële sector de belangrijkste was. Hierna bepaalde hij de wortels van het gelineariseerde stelsel die de stabiliteit van het model bepalen. Het bleek dat de dominante wortel van het stelsel nauwelijks van 1 verschilde, zodat volgens dit criterium het systeem nauwelijks stabiel is. Een nadere analyse leert dan echter dat de beginvoorwaarden een zodanige invloed hebben dat de term in de dominante wortel klein is in vergelijking tot die in wortels met cen kleinere absolute waarde.

Was het resultaat van de eerste simulatie niet erg bevredigend, dan is dit wel te verklaren omdat de exogene variabelen hun trendwaarden volgden en de storingstermen verondersteld werden 0 te zijn. Daarom hebben Adelman en Adelman de simulatie herhaald met de exogene variabelen die afwijkingen van hun trendwaarde hadden en met storingstermen die niet 0 waren; voor afwijkingen en storingstermen koos men willekeurige getallen met een realistische standaarddeviatie. Het resultaat was dat men nu over de 100-jaar periode fluctuaties in de endogene variabelen te zien kreeg die qua amplitude en periode realistisch zijn. Een nadere analyse van de vertragingen in de fluctuaties van de endogene variabelen gaf te zien dat deze overeenkwamen met vertragingen zoals die in de conjunctuurcyclus waargenomen zijn. Op deze wijze werd dus duidelijk dat de dynamische eigenschappen van het Klein-Goldberger model overeenkomen met de werkelijkheid. Verder werd de waarde van de suggestie van Slutsky, dat conjunctuurfluctuaties van een regelmatig patroon kunnen ontstaan uit sommatie van relatief kleine willekeurige schokken van exogene variabelen en storingstermen, nog eens bevestigd.

Dezelfde resultaten hadden misschien ook wel (maar dan met zeer veel moeite) op de gebruikelijke wiskundige manier afgeleid kunnen worden, maar de simulatie-aanpak is in dit geval veel efficiënter omdat hij zich concentreert op wat gebeurt indien men realistische waarden voor de exogene variabelen gebruikt, terwijl de methode van wiskundige analyse van de dynamische eigenschappen veel algemener te werk gaat omdat men uitdrukkingen moet afleiden die geldig zijn voor alle waarden van de exogene variabelen.

\section{Een simulatie van een teruggang in de Amerikaanse economie}

Een andere interessante simulatie-studie is die van Duesenberry, Eckstein en Fromm [5]. Deze studie heeft eveneens betrekking op een model voor de Verenigde Staten, maar het model is slechts geldig voor een depressie-situatie. Het model is dynamisch en niet-lineair; verder zijn de perioden kwartalen in plaats van jaren zoals in het Klein-Goldberger model. De simulatie heeft verder alleen plaats voor 8 perioden, dat is dus 2 jaar, omdat men in het bijzonder het verloop van een recessie die in 1957 begon wilde bestuderen. Het doel van de simulatie is hier in de eerste plaats om na te gaan wat de gevolgen zijn van verschillende vormen van automatische stabilisatoren van de economie.

Als punten van uitgang zijn weer gekozen een gegeven model en diverse mogelijkheden t.a.v. de exogene variabelen, in dit geval de autonome componenten van het nationaal product, te weten overheidsuitgaven en autonome investeringen. Twee patronen voor de autonome componenten worden gebruikt; het eerste stelt een pseudo-realistische situatie voor waarin de autonome component eerst daalt en daarna weer stijgt, terwijl het tweede patroon een ramp-situatie weergeeft waarin de autonome componenten gedurende de gehele beschouwde periode 
dalen. De berekeningen hebben weer periode na periode plaats. Een derde experiment had plaats met autonome componenten die na de eerste periode daalden met bijna $10 \%$ en daarna gelijk bleven.

Voor de ramp-situatie werd nagegaan wat de gevolgen zouden zijn van het invoeren van nieuwe automatische stabilisatoren, $\mathrm{nl}$. een verhoogde uitkering van de werkloosheidsverzekering en van de automatische aanpassing van de belastingtarieven aan een daling van het nationaal product. Duidelijk werd dat invoering van deze stabilisatoren de teruggang van het nationaal product kan beperken maar niet geheel kan voorkomen. Verder bleek o.a. dat de huidige automatische stabilisatoren niet in staat zijn het systeem terug te brengen tot een situatie van volledige werkgelegenheid. Introductie van storingstermen leidde niet tot belangrijke wijzigingen in deze conclusies.

Naar aanleiding van deze studie zou men kunnen zeggen dat simulatie en de normale voorspelling en projectie niet ver van elkaar af liggen. Bij de simulatie legt men de nadruk op de voorwaardelijke formulering van de gegevens, in de eerste plaats van de exogene variabelen en verder ook van de parameters van het model, terwijl deze bij de voorspelling verondersteld worden vast te staan. Ook is het de berekeningswijze, het periode voor periode berekenen van de variabelen, die typerend is voor de simulatie.

Het doet enigszins vreemd aan dat in deze studie slechts automatische stabilisatoren beschouwd worden en geen maatregelen die het aktief ingrijpen van de overheid noodzakelijk maken, zoals een verhoging der overheidsuitgaven. Dit wil dus zeggen dat de economische politiek beperkt blijft tot een wijziging van de structuur van het stelsel; manipulatie van de exogene variabelen die de overheid beheerst, de instrumenten van de economische politiek, wordt niet beschouwd. Het kan zijn dat de oorzaak hiervan is een vrijwillige beperking van het studieobject van de zijde van de auteurs; een factor die misschien ook van belang is, is het feit dat openlijk ingrijpen van de overheid in het economisch leven in de Verenigde Staten politiek minder aanvaardbaar is. In de volgende studie, ook van Amerikaanse origine, wordt wel een grote rol aan actief overheidsingrijpen toegedacht, maar deze heeft dan ook betrekking op een onderontwikkeld gebied.

\section{Een simulatie met een ,computer model" voor een onderontwikkeld land}

De volgende studie die hier aan de orde komt is het boek van Holland en Gillespie [7], dat de economische ontwikkeling van een onderontwikkeld land, India, ten onderwerp heeft. De problemen zijn van tweeërlei aard: wat is de beste economische politiek om de economische ontwikkeling te bevorderen en welke maatregelen kunnen genomen worden om de betalingsbalans zoveel mogelijk in evenwicht te houden. Waren de twee vorige studies gebaseerd op "conventionele" econometrische modellen, hetgeen betekent dat het aantal vergelijkingen en variabelen relatief beperkt blijft, hier bestaat het model slechts in de vorm van een programma voor de electronische rekenmachine, omdat het te gedetailleerd is om op de normale wijze gepresenteerd te worden.

Het model bevat 5 sectoren die verondersteld worden elk een homogeen produkt te produceren. Prijzen en inkomens in de verschillende sectoren hangen af van de vraag naar de betreffende goederen en de gebruikte capaciteit in de sectoren. De produktie-capaciteit van de sectoren hangt af van de investeringen in deze sectoren; investeringen leiden pas na vertragingen tot verhoogde capaciteit. 
De gebruikte perioden zijn klein, $1 / 20$ jaar, wat het voordeel heeft van een mogelijkheid tot weergave van snelle reacties. Het gehele tijdperk waarover simulatie plaatsvindt is 15 à 20 jaar.

In dit ingewikkelde model wordt nu geëxperimenteerd met verschillende patronen in de investering in de 5 sectoren. In het bijzonder wordt aandacht besteed aan de stijgingen in het nationaal produkt, de prijsstijgingen en de tekorten op de betalingsbalans die resulteren uit de verschillende patronen van de investeringen. De gevolgen van het instellen van additionele maatregelen worden nagegaan, zoals investeringsplafonds, loonpolitiek, belastingpolitiek en devaluatie. De toepassing van deze maatregelen kan afhankelijk gemaakt worden van de omstandigheden, bijv. investeringsplafonds worden dan slechts toegepast als het prijsniveau met meer dan $2 \%$ per jaar stijgt. Dit alles wordt nog bezien bij verschillende waarden van elasticiteiten.

Met behulp van de simulatie kan men dan die economische politiek uitkiezen die in het licht van de experimenten het aantrekkelijkst lijkt. Men probeert dus zoveel verschillende patronen van sector-investeringen aangevuld met additionele maatregelen tot men een zodanig patroon gevonden heeft dat tot de meest gewenste ontwikkeling van de economie lijkt te leiden.

Het voordeel van deze aanpak is dat met veel meer factoren expliciet rekening kan worden gehouden. Zo is een van de factoren in het model aanpassing voor optimisme of pessimisme bij de bepaling van de verwachte opbrengst van het geinvesteerde kapitaal. Aan de andere kant is het heel moeilijk de invloed van al deze factoren te schatten. Het is duidelijk dat het samenstellen van zulk een gedetailleerd model veel meer werk met zich meebrengt dan dat van de gebruikelijke econometrische modellen. Mits ze goed gefundeerd zijn, kunnen meer gedetailleerde modellen echter moeilijk tot slechtere resultaten leiden dan minder gedetailleerde.

Het is interessant de wijze waarop de beste economische politiek bepaald wordt bij simulatie te vergelijken met die bij andere aanpakken. Nemen we bijv. de aanpak van de lineaire beslissingsregels voorgesteld door Theil [12], die deze zou willen toepassen voor de ontwiklselingsprogrammering, zie [13]. In deze aanpak worden de preferenties t.a.v. de meest gewenste ontwikkeling benaderd door een $\mathrm{kwadratische}$ preferentiefunktie, die gemaximeerd wordt onder nevenvoorwaarden; de laatste worden gevormd door de vergelijkingen van het econometrisch model dat dan lineair moet zijn. Deze opzet heeft het voordeel dat ze tot tamelijk gemakkelijk te bepalen beslissingen leidt; verder geeft de aanpak ook optimale beslissingen in het geval storingstermen in het model optreden.

De simulatie-aanpak is experimenteel en daarom minder systematisch: men zoekt de beschikbare mogelijkheden af tot men denkt tot de beste oplossing gekomen te zijn. Een nadeel is dan dat men nooit alle mogelijkheden uitputtend kan nagaan, zodat men nict zeker weet of men wel de beste oplossing gevonden heeft; dit is echter waarschijnlijk eerder een theoretisch dan een praktisch be$z$ waar. De lineaire beslissingsregels hebben daarentegen het praktische nadeel dat het heel moeilijk is een adequate specificatie te vinden voor de preferentiefunktie. Voor deze specificatie is het nodig de bewindslieden eerst te interviewen over hun preferenties in alle mogelijke situaties en de resultaten weer te geven in een $\mathrm{kwadratische}$ funktie. De simulatietechniek is veel directer doordat men de bewindslieden de resultaten direct kan voorleggen (waaraan natuurlijk een schifting 
van relevante en irrelevante uitkomsten vooraf moet gaan). Verder heeft simulatie het voordeel dat het model niet noodzakelijkerwijs lineair moet zijn zoals bij lineaire beslissingsregels; integendeel, allerlei niet-lineariteiten kunnen zich voordoen mits een periode-voor-periode berekening van de uitkomsten maar mogelijk blijft. De lineaire beslissingsregels zijn theoretisch natuurlijk eleganter, maar het is waarschijnlijk dat, voorzover het om praktische toepassing gaat, de simulatie-aanpak de voorkeur verdient.

\section{Enige slotopmerkingen}

Simulatie met macro-economische modellen is een tamelijk nieuw onderwerp; er zijn nog niet veel studies op dit gebied verschenen. Het is waarschijnlijk dat de betekenis van simulatie op dit gebied in de komende jaren zal toenemen, alleen al door het feit dat steeds meer economen vertrouwd raken met en de beschikking krijgen over electronische rekenmachines. Een ontwikkeling naar meer gedetailleerde modellen, van het type van de laatst besproken studie, lijkt waarschijnlijk.

Misschien dat door verdere detaillering van de modellen op de duur een vruchtbare samenwerking tussen macro- en micro-economie kan ontstaan. De ontwikkeling van micro-economische simulatie-studies is reeds op gang gekomen. Een voorbeeld hiervan is het werk van Orcutt, c.s., [9], dat een micro-economische simulatiestudie op basis van demografische modellen bevat.

Ook op het gebied van de onderneming en de bedrijfstak heeft de simulatie reeds vaste voet gekregen. Als voorbeeld wordt hier genoemd het werk van Cyert en March, c.s., [4], en dat van Cohen [3]. In de laatstgenoemde twee werken en in [11] wordt tevens de constructie van een "computer model" nader uiteengezet. De talloze toepassingen op het gebied van de operationele research vallen geheel buiten het bestek van dit artikel. Voor een Russische visie op het gebruik van simulatie, zie het artikel van Cherniak [2].

Uit het voorgaande zou men kunnen concluderen dat het gebruik van simulatietechnieken nieuwe hoop doet rijzen voor verbeteringen van de economische analyse, van economische voorspellingen en van economische politiek. Want zulke verbeteringen zijn nog steeds wel nodig.

\section{I TER A T U U R}

[1] I. Adelman en F. L. Adelman, "The Dynamic Properties of the Klein-Goldberger Model". Econometrica, Vol. 27 (1959), No. 4, p. 596-625.

[2] I. I. Cherniak, "The Electronic Simulation of Information Systems for Central Planning”. Economics of Planning, Vol. 3 (1963), p. 23-40.

[3] K. J. Cohen, Computer Models of the Shoe, Leather, Hide Sequence. Englewood Cliffs, N.J., Prentice-Hall, 1960.

[4] R. M. Cyert en J. C. March, A Behavioral Theory of the Firm. Englewood Cliffs, N.J., Prentice-Hall, 1963.

[5] J. Duesenberry, C. Eckstein en G. Fromm, „A Simulation of the United States Economy in Recession". Econometrica, Vol. 28 (1960), No. 4, p. 749-809.

[6] A. S. Goldberger, Impact Multipliers and Dynamic Properties of the Klein-Goldberger Model. Amsterdam, Noord-Hollandse Uitgeversmaatschappij, 1959.

[7] E. F. Holland en R. W. Gillespie, Experiments on a Simulated Underdeveloped Economy: Development Plans and Balance of Payments Policies. Cambridge (Mass.), The M.I.T. Press, 1963.

[8] L. R. Klein en A. S. Goldberger, An Econometric Model of the United States 1929-1952. Amsterdam, Noord-Hollandse Uitgeversmaatschappij, 1955. 
[9] G. H. Orcutt, M. Greenberger, J.Korbel en A. M. Rivlin, Micro-Analysis of Socio-Economic Systems: A Simulation Study. New York, Hasper \& Brothers, 1961.

[10] C. van de Panne en H. Lange, "Scheefheidstoetsen”. Statistica Neerlandica, Jrg. 12 (1958) No.4, p. 255-264.

[11] R. Rosensthiel en A. Chouila-Houri, Les choix économiques, décisions séquentielles et simulation. Parijs, Dunod, 1960.

[12] H. Theil, Optimal Decision Rules for Government and Industry. Amsterdam, Noord-Hollandse Uitgeversmaatschappij, 1964.

[13] H. Theil, "Decision Rules and Simulation Techniques in Development Programming". Rapport 6321 van het Econometrisch Instituut, Rotterdam.

[14] H. Theil en J. C. G. Boot, "The Final Form of Econometric Equation Systems". Review of the International Statistical Institute, Vol. 30 (1962), p. 136-152. 